\title{
Identifying recharge under subtle ephemeral features in a flat-lying semi-arid region using a combined geophysical approach
}

\author{
Brady A. Flinchum ${ }^{1}$, Eddie Banks ${ }^{2}$, Michael Hatch ${ }^{2,3}$, Okke Batelaan $^{2}$, Luk J. M. Peeters ${ }^{1}$, and Sylvain Pasquet ${ }^{4}$ \\ ${ }^{1}$ Commonwealth Scientific Industrial Research Organization (CSIRO), Deep Earth Imaging Future Science Platform \& \\ Land and Water, Urrbrae, 5064, Australia \\ ${ }^{2}$ National Centre for Groundwater Research and Training, College of Science and Engineering, \\ Flinders University, Adelaide, 5001, Australia \\ ${ }^{3}$ Department of Geosciences, School of Physics, University of Adelaide, Adelaide, Australia \\ ${ }^{4}$ Université de Paris, Institut de physique du globe de Paris, CNRS, 75005 Paris, France
}

Correspondence: Brady A. Flinchum (brady.flinchum@csiro.au)

Received: 25 October 2019 - Discussion started: 2 January 2020

Revised: 9 June 2020 - Accepted: 19 June 2020 - Published: 9 September 2020

\begin{abstract}
Identifying and quantifying recharge processes linked to ephemeral surface water features is challenging due to their episodic nature. We use a combination of wellestablished near-surface geophysical methods to provide evidence of a surface and groundwater connection under a small ephemeral recharge feature in a flat, semi-arid region near Adelaide, Australia. We use a seismic survey to obtain Pwave velocity through travel-time tomography and S-wave velocity through the multichannel analysis of surface waves. The ratios between $\mathrm{P}$-wave and $\mathrm{S}$-wave velocities are used to calculate Poisson's ratio, which allow us to infer the position of the water table. Separate geophysical surveys were used to obtain electrical conductivity measurements from timedomain electromagnetics and water contents from downhole nuclear magnetic resonance. The geophysical observations provide evidence to support a groundwater mound underneath a subtle ephemeral surface water feature. Our results suggest that recharge is localized and that small-scale ephemeral features may play an important role in groundwater recharge. Furthermore, we show that a combined geophysical approach can provide a perspective that helps shape the hydrogeological conceptualization of a semi-arid region.
\end{abstract}

\section{Introduction}

Understanding groundwater recharge mechanisms and surface-water-groundwater connectivity is crucial for sustainable groundwater management (Banks et al., 2011; Brunner et al., 2009). In semi-arid areas, recharge has been shown to occur in focused regions beneath perennial streams and lakes, and ephemeral streams and ponds (Cuthbert et al., 2016; Scanlon et al., 2002, 2006). However, identifying localized regions of groundwater recharge remains challenging.

Many aquifers in semi-arid areas receive a significant portion of their recharge from adjacent mountain ranges (Bresciani et al., 2018; Earman et al., 2006; Wilson and Guan, 2004; Winograd et al., 1998). In this common scenario, recharge can occur via groundwater flow from the mountain range directly into the aquifer - implying a significant lateral groundwater connection with the adjacent mountain range (Markovich et al., 2019). Alternatively, precipitation from the mountain range flows out and across the semi-arid basin as surface water and recharges the aquifer via river infiltration processes - implying a vertical connection between surface and groundwater (Bresciani et al., 2018; Brunner et al., 2009; Winter et al., 1998).

Groundwater recharge processes span a wide range of spatial and temporal scales making them difficult to quantify (Scanlon et al., 2002). Recharge rates are traditionally quantified using physical, tracer, or modelling techniques (Scan- 
lon et al., 2002). Physical techniques include carefully measuring fluxes and evapotranspiration along various reaches of a river or stream (Abdulrazzak, 1995; Lamontagne et al., 2014), by calculating aquifer water level response times (e.g. water table fluctuation method) (Cuthbert et al., 2019), or through stream hydrograph separation (Banks et al., 2009; Chapman, 1999; Cuthbert et al., 2016). Common tracer techniques include the use of stable isotopes of hydrogen and oxygen (Lamontagne et al., 2005; Taylor et al., 1992; Winograd et al., 1998), quantifying chemical signatures that have accumulated from past human activities (e.g. chlorofluorocarbons and sulfur hexafluoride) (Cook et al., 1996), and measuring environmental tracers such as chloride (Allison et al., 1990; Anderson et al., 2019; Crosbie et al., 2018) and radon (Bertin and Bourg, 1994; Genereux and Hemond, 2010; Hoehn and Gunten, 1989). Lastly, numerical modelling is used to estimate recharge over global scales (Gleeson et al., 2012; Scanlon et al., 2006) and test existing hydrogeological conceptualizations (Xie et al., 2014).

Quantifying recharge processes in ephemeral ponds or streams in semi-arid regions is particularly difficult because flooding events are episodic (Shanafield and Cook, 2014). The infrequency and variable size of flooding events makes it difficult to monitor, quantify, or even identify whether groundwater recharge has occurred. Furthermore, infiltration is a different process than recharge. Groundwater recharge must be confirmed by a response in the water table, whereas water that has infiltrated might have been taken up by vegetation or lost to evaporation. Larger ephemeral rivers flood frequently so equipment can be installed and be ready when an event occurs (Dahan et al., 2007, 2008). On the other hand, it is more difficult to capture recharge events of smaller ephemeral tributaries; as a result, the recharge mechanisms of these features are less understood. These smallerscale features are common on Earth's surface. It has been shown that $69 \%$ of first-order streams and $\sim 34 \%$ of larger fifth-order rivers below $60^{\circ}$ latitude are ephemeral (Acuña et al., 2014; Raymond et al., 2013). Thus, even if small ephemeral features only provide small amounts of groundwater recharge during individual events, their large spatial distribution means that they could be important to recharge processes of a given region.

Small ephemeral features are an ideal target for nearsurface geophysical surveys. A wide range of existing and standardized geophysical techniques have been used in hydrological studies (e.g. Robinson et al., 2008; Siemon et al., 2009; Parsekian et al., 2015). To highlight surface and groundwater connections, geophysical methodologies commonly rely on time-lapse measurements. This is because the infiltration of groundwater causes changes in geophysical properties on the order of days or months (i.e. the geology stays constant). Time-lapse electrical resistivity measurements have been used to observe and monitor recharge pathways (Carey and Paige, 2016; Singha and Gorelick, 2005; Johnson et al., 2012; Valois et al., 2016; Thayer et al., 2018;
Kotikian et al., 2019) and can highlight preferential flow paths. These methods are still handicapped by the fact that they still require the burial or setup of the geophysical equipment prior to a natural recharge (Kotikian et al., 2019; Thayer et al., 2018) or a man-made event (Carey and Paige, 2016; Claes et al., 2019). It is still challenging to find a suitable geophysical approach that can be deployed rapidly (that is, without a time-lapse setup) to determine whether an ephemeral drainage feature is acting as a groundwater recharge feature.

The aim of this study is to use a combination of wellestablished near-surface geophysical methods to provide evidence of a surface and groundwater connection of a small, shallow, and subtle ephemeral feature in a low-lying semiarid landscape without time-lapse measurements. We used a single seismic survey to obtain P-wave velocity through seismic refraction tomography (SRT) (Sheehan et al., 2005; Zelt et al., 2013) and S-wave velocity through the multichannel analysis of surface waves (MASWs) (Park et al., 1999; Pasquet and Bodet, 2017) to calculate Poisson's ratio, which allowed us to infer the position of the water table. A separate survey was used to obtain bulk electrical conductivity measurements from transient electromagnetics (TEMs) (Parasnis, 1986; Reynolds, 2011; Telford et al., 1990). Water contents and $T_{2}$ relaxation times (time constant for the decay of transverse magnetization) were acquired using downhole nuclear magnetic resonance (NMR) (Walsh et al., 2013). We used this combination of standard geophysical measurements to show that small-scale ephemeral features are likely to contribute to the localized replenishment of groundwater in shallow unconfined aquifers in this low-lying semi-arid environment.

\section{Site description}

The North Adelaide Plains (NAP) are located north of the city of Adelaide, Australia, and are part of the St Vincent Basin, a geological basin underlying the area between the Yorke Peninsula and the Mount Lofty Ranges in South Australia (Fig. 1). The St Vincent Basin is a north-south-trending basin that is characterized by low topographic relief between 0 and $200 \mathrm{~m}$ elevation above sea level (Smith et al., 2015). The NAP are bound by the Mount Lofty Ranges to the east and their northern boundary is marked by the Light River (Fig. 1). Land-use in the NAP is predominantly dryland agriculture with mixed farming (sheep and rotational cropping of wheat, barley, and canola) (Goyder Institute for Water Research, 2016). Potential evaporation is high and the average rainfall is low, averaging around $445 \mathrm{~mm} \mathrm{yr}^{-1}$, with an average daily temperature of $21.6^{\circ} \mathrm{C}$ (Bresciani et al., 2018). The combination of low rainfall and high evaporation rates in the NAP implies that the source water in the aquifers is from the Mount Lofty Ranges, where the average rainfall is $983 \mathrm{~mm} \mathrm{yr}^{-1}$ (Bresciani et al., 2018). Rainfall is winterdominated (May to August), which suggests that recharge is 


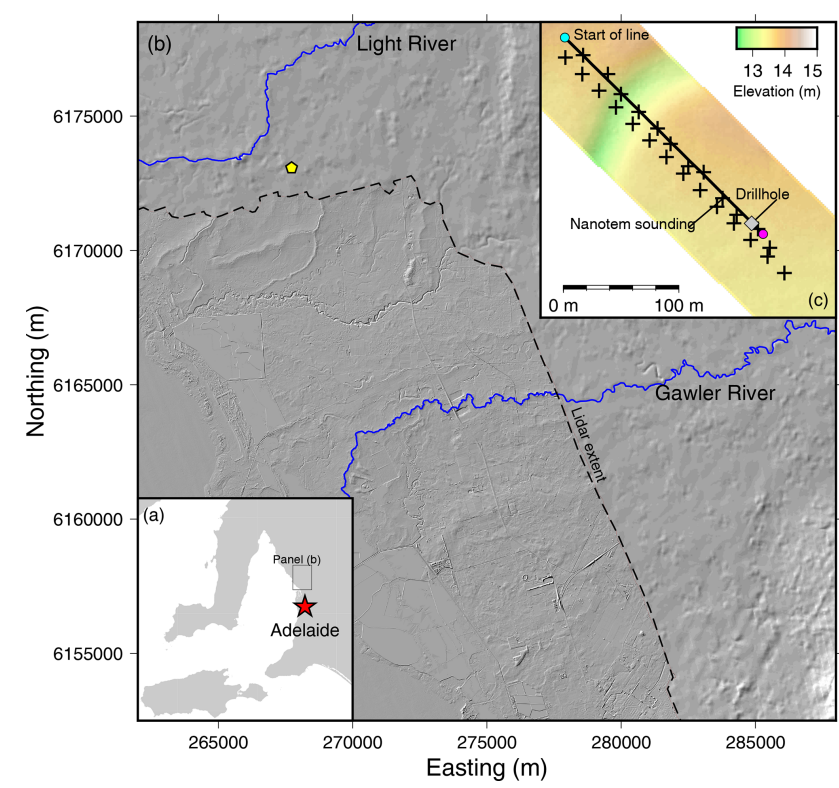

Figure 1. (a) Inset map showing the general location of the study area relative to the city of Adelaide, South Australia. (b) Hill-shaded topographic relief with the lidar data overlaid. The northern extent of high-resolution lidar DEM data is marked with a dashed line. The yellow star represents the site location. The Light and Gawler Rivers are shown in blue. (c) High-resolution topography (drone based) of the field area where the geophysical testing took place. The thick black line is the seismic line, where the cyan dot is the start and the magenta dot is the end. Black crosses represent the location of NanoTEM soundings. The grey square is the shallow drill hole location and also where the downhole NMR data were collected.

also seasonal (Batlle-Aguilar et al., 2017; Bresciani et al., 2018).

Lidar of the NAP shows that within this low-relief landscape there are many small ephemeral surface drainage features (Fig. 1). These subtle drainage features are visible in the hill-shaded lidar and indicate that surface water runoff is likely to flow towards these ephemeral drainage features and toward the larger streams after precipitation events (Fig. 1b). These ephemeral features are not monitored because they fall below the resolution of the $30 \mathrm{~m}$ Shuttle Radar Topography Mission (SRTM) elevation data (Fig. 1b). The near-surface Quaternary aquifers are typically used for stock and domestic purposes and have salinity ranges between 2000 and $13000 \mathrm{mg} \mathrm{L}^{-1}$ (Department for Water, 2010; Goyder Institute for Water Research, 2016). The near-surface aquifers are only monitored because they present a risk of waterlogging and soil salinization (Department for Water, 2010).

Most of the water that recharges the NAP aquifers comes from the Mount Lofty Ranges to the east, supported by the fact that in between streams you find high-salinity water, which suggests the occurrence of diffuse recharge - see the conceptual model in Bresciani et al. (2018; Fig. 14). It has been shown on the basis of multiple lines of evidence that water flows from the Mount Lofty Ranges onto the NAP through ephemeral rivers and streams and recharges the underlying aquifers via vertical infiltration (Bresciani et al., 2018). In this conceptual model, recharge is mostly localized and occurs along the main rivers and streams. This conceptual model is supported by lower groundwater chloride concentrations surrounding Gawler River and Little Para River in both the Quaternary and Tertiary aquifers and the piezometric surfaces that show groundwater moving away from the rivers (losing river conditions) and into the underlying aquifers (Bresciani et al., 2018). Prior to this study, it was argued that the aquifers of the NAP were recharged through a lateral groundwater connection with the rocks underlying the Mount Lofty Ranges. This concept was supported by an increase in groundwater ages away from the Mount Lofty Ranges and stable isotopes indicating some evaporation prior to infiltration (Batlle-Aguilar et al., 2017). It is important to note that the age and isotope data support the mountain front recharge conceptual model of Bresciani et al. (2018) equally well.

Our study site is located on a private farm, $44 \mathrm{~km}$ northwest of Adelaide, and is between the Light and Gawler rivers (Fig. 1). In May of 2018, as part of a regional study of the shallow water table, 47 shallow holes were drilled across the northern region of the NAP with a small truck-mounted Rockmaster drill rig (Hatch et al., 2019). We used these preexisting sites to select a location where we knew the water table was within a range of 3-10 $\mathrm{m}$ to increase the likelihood of imaging the water table with the seismic data. The existing drill hole would also provide ground-truthing to the geophysical data. Thus, our study transect for the near-surface geophysical surveys was located adjacent to one of these drill hole sites where we had manual water level measurements, soil samples, and downhole NMR logs. The $235 \mathrm{~m}$ long transect line was positioned so that it crossed a small ephemeral topographic feature that is only visible on a map with highresolution elevation data collected via drone (Fig. 1c).

\section{Methods}

To aid in geophysical interpretation and reduce ambiguities, it is important to "ground-truth" near-surface geophysical data with drilling results (Flinchum et al., 2018; Gottschalk et al., 2017; Orlando et al., 2016; West et al., 2019) or to corroborate them by other independent geophysical measurements. In this study, we combined hydrogeological observations with multiple geophysical measurements to obtain different geophysical parameters, specifically bulk electrical conductivity from TEM, P-wave velocity from SRT, Swave velocity from MASW, and water contents from downhole NMR. In April 2018, the shallow drill hole was logged with a downhole NMR system (Vista Clara Dart) and the water level was measured by hand. Only a week after the 
seismic data were collected, a separate campaign was carried out to collect 26 TEM soundings along the same profile (Fig. 1c). In this paper, we use these geophysical methods to infer a surface-water-groundwater connection without timelapse measurements. In this section we briefly describe the theory behind the geophysical methods and how the measurements are influenced by various hydrological properties. Additional figures and details pertaining to the processing of the geophysical data set can be found in the Supplement.

\subsection{Topography acquisition}

At our study site, no lidar imagery was available. Highresolution imagery of the small study area $(\sim 9$ ha) was thus acquired with a DJI Phantom 4 Pro unmanned aerial vehicle (UAV). The UAV flew a grid pattern over the study area at an elevation of $30 \mathrm{~m}$ a.g.l. (above ground level) and collected a photo data set of 834 images. Georeferencing was undertaken using a Trimble R10 global positioning system (GPS) real-time kinematic (RTK) survey with 65 ground control points located within the study area and provided a georeferencing root mean square error $(\mathrm{rms})$ of $0.153 \mathrm{~m}$. The captured photos were processed using the photogrammetry Pix4D software package (Pix4Dmapper Pro version 3.2, $2017)$ to generate a high-resolution $(0.8 \mathrm{~cm}$ per pixel) digital surface model (DSM). As the study area was a fallow field at the time of the survey, the DSM was treated as a digital elevation model (DEM) as there was very little vegetation present. The generated DEM was re-sampled to a $0.5 \mathrm{~m}$ DEM (Fig. 1) that was used to extract the elevation profile along the geophysical transect.

\subsection{Seismic refraction tomography}

Seismic refraction is an active source geophysical method that estimates seismic velocity. A seismic refraction survey provides a spatial distribution of P-wave velocity (energy propagating along the direction of travel). In a shallow seismic refraction survey, the time taken for the energy to travel from a source to each individual receiver, called a travel time, is measured. The subsurface velocity structure controls the travel times so they can be inverted to retrieve the subsurface P-wave velocity structure using a forward model and an inversion scheme (Sheehan et al., 2005; Zelt et al., 2013). $\mathrm{P}$-wave velocity is controlled by the elastic properties of the material, porosity, and saturation (Berryman et al., 2002; Hashin and Shtrikman, 1963). If the pore space is filled with a fluid, in our case water (regardless of salinity), then the $\mathrm{P}$-wave velocity is greater than if the pore space is not filled with fluid (Bachrach and Nur, 1998; Desper et al., 2015; Gregory, 1976; Nur and Simmons, 1969).

In this survey, we used 48 geophones spaced at $5 \mathrm{~m}$, which produced a $235 \mathrm{~m}$ long profile. The source was a $40 \mathrm{~kg}$ accelerated weight, striking a $20 \mathrm{~cm} \times 20 \mathrm{~cm} \times 2 \mathrm{~cm}$ steel plate at every geophone. To increase the signal-to-noise ratio, eight shots were stacked at each of the 80 locations. The travel times were picked manually (Figs. S1 and S2 in the Supplement) and inverted for P-wave velocity using the refraction module in the Python Geophysical Inversion and Modeling Library (pyGIMLi) (Rücker et al., 2017). The forward model is based on the shortest path algorithm (Dijkstra, 1959; Moser, 1991; Moser et al., 1992). PyGIMLi utilizes a deterministic Gauss-Newton inversion scheme and incorporates a data weight matrix (Rücker et al., 2017). We populated the data weight matrix using reciprocal travel times (Fig. S2). To initialize the inversion, we used a gradient model that had a velocity of $0.4 \mathrm{~km} \mathrm{~s}^{-1}$ at the surface and $2 \mathrm{~km} \mathrm{~s}^{-1}$ at a depth of $40 \mathrm{~m}$. To quantify uncertainty, we incorporated a bootstrapping algorithm on the travel-time picks (details in the Supplement). The model fits are determined by a $\chi^{2}$ misfit, which incorporates our picking errors and an rms error (details in Supplement).

\subsection{Multichannel analysis of surface waves}

At the Earth's surface, most of the elastic energy travels as surface waves. Surface waves are the largest amplitude events that are recorded in both active source seismic acquisition and earthquake records. Surface waves are caused by interactions of the body waves ( $\mathrm{P}$ waves and $\mathrm{S}$ waves) and the boundary conditions that only exist at the surface (Stein and Wysession, 2003). There are two types of surface waves: Love waves and Rayleigh waves (for a detailed review on surface waves, the reader is referred to Stein and Wysession, 2003, and Lowrie, 2007). In this study we take advantage of the dispersive nature of Rayleigh waves (Park et al., 1999; Pasquet and Bodet, 2017; Xia et al., 1999, 2003). Furthermore, Rayleigh waves propagate at velocities mostly driven by the S-wave velocity of the medium. The dispersion of Rayleigh waves can be measured by picking the phase velocity as a function of frequency (Park et al., 1999; Xia et al., 2003). The phase velocity of lower frequencies (longer wavelengths) will be influenced by deeper S-wave velocity structures, whereas higher frequencies will be influenced by shallower structures. These frequency-dependent phase velocities can then be inverted for one-dimensional (1D) Swave velocity models at low computational costs (Pasquet and Bodet, 2017).

In this study, we use the acquisition setup from the refraction survey to analyse the dispersion of surface wave energy. This approach produces a pseudo two-dimensional (2D) section comprised of 41 1D S-wave velocity profiles, spaced every $5 \mathrm{~m}$ starting at $17.5 \mathrm{~m}$ from the start of the profile. To build the pseudo 2D profile we used the Surface Wave Inversion and Profiling (SWIP) package (Pasquet and Bodet, 2017). First, the seismic data are resorted and windowed to sample 1D vertical slices of the subsurface. Once windowed, the sorted seismic data are transformed into the frequencyphase velocity domain using a slant stack (Mokhtar et al., 1988). To increase the depth of investigation, similar disper- 
sion curves from different shots are stacked together (Neducza, 2007). Once the dispersion curves are constructed they are picked and an uncertainty associated with each pick is defined (O'Neil, 2003) (Fig. S4). To construct our dispersion curves, we used $40 \mathrm{~m}$ windows (eight stations) and ensured a $5 \mathrm{~m}$ offset between the source and first channel to avoid near-source effects. The picks and corresponding uncertainty for each windowed dispersion curve are inverted using a Monte Carlo approach and the neighbourhood algorithm (Sambridge, 1999; Wathelet et al., 2004). We ran 15000 inversions for each of our dispersion curves and averaged the 1000 best-fitting S-wave velocity models to build final 1D models (Fig. S5) every $5 \mathrm{~m}$ (more details about processing can be found in the Supplement). Finally, the individual 1D S-wave profiles are combined into a pseudo-2D section (Pasquet et al., 2015a, b; Pasquet and Bodet, 2017).

\subsection{Poisson's ratio}

Locating the water table of the unconfined aquifer over large spatial scales is challenging and is traditionally done by drilling down to the water table and interpolating manual water level measurements between drill hole locations. Building a detailed water table map requires many measurements and can be limited by logistical or financial constraints. Here, we exploit the fact that $\mathrm{P}$-wave velocities increase when a material is saturated and the $\mathrm{S}$-wave velocities remain relatively unchanged (Bachrach and Nur, 1998; Desper et al., 2015; Gregory, 1976; Nur and Simmons, 1969).

Poisson's ratio is a unitless elastic property that describes how much a material will deform in the direction perpendicular to an applied stress. Poisson's ratio can be calculated from P-wave and S-wave velocities (Eq. 1).

$$
v=\frac{V_{\mathrm{p}}^{2}-2 V_{\mathrm{s}}^{2}}{2\left(V_{\mathrm{p}}^{2}-V_{\mathrm{s}}^{2}\right)}
$$

In Eq. (1), $V_{\mathrm{p}}$ is $\mathrm{P}$-wave velocity, $V_{\mathrm{s}}$ is $\mathrm{S}$-wave velocity, and $v$ is Poisson's ratio. Poisson's ratio for geologic materials ranges from 0 to 0.5 . Poisson's ratio increases as fluid saturation increases (Bachrach et al., 2000; Dvorkin and Nur, 1996; Nur and Simmons, 1969; Salem, 2000). Furthermore, Poisson's ratio is an indicator for determining the difference between gas and fluid saturated materials (Gregory, 1976; Pasquet et al., 2016) and has been shown to be useful to track pressure changes (Prasad, 2002), map the water table depth (Bachrach et al., 2000; Pasquet et al., 2015a; Salem, 2000; Uyanık, 2011), and differentiate gas and fluid in hydrothermal systems (Pasquet et al., 2016). To image the water table with Poisson's ratio, the conceptual model of the geology must be simplified (i.e. no lateral changes) and requires that there are at least a few metres of unsaturated sediments overlying the saturated region to generate a vertical contrast in elastic properties; our study site satisfies both these conditions.

\subsection{Nuclear magnetic resonance}

Nuclear magnetic resonance (NMR) capitalizes on the existence of a measurable magnetic moment produced by the rotation of hydrogen protons contained in water molecules. At equilibrium, the direction of the magnetic moment points in the direction of a background magnetic field. An NMR measurement emits an electromagnetic pulse at a specific frequency (called Larmor frequency) in order to force protons out of equilibrium. When the excitation pulse ends, the protons return to equilibrium in a process called relaxation. During relaxation, a measurable resonating magnetic moment that decays exponentially can be measured (Bloch, 1946; Brownstein and Tarr, 1979; Torrey, 1956). The initial magnitude of the signal is directly proportional to the number of protons excited, which in near-surface exploration come mostly from groundwater, and the rate of decay (i.e. the relaxation time $T_{2}$ ) is related to the pore size. Thus, NMR has the ability to directly measure the amount of groundwater within its measurement volume. For a thorough review of NMR theory, the reader is referred to Behroozmand et al. (2015) and textbooks dedicated to the theory of NMR (Coates et al., 1999; Dunn et al., 2002; Levitt, 2001).

The decay rate, described by $T_{2}$, is a function of two distinct processes: the bulk relaxation and the surface relaxation (Brownstein and Tarr, 1979; Cohen and Mendelson, 1982; Grunewald and Knight, 2012). The surface relaxation is controlled by an intrinsic property called the surface relaxivity and the surface-to-pore volume ratio. Surface relaxivity describes a material's ability to intensify relaxation. The dependence on the surface-to-pore volume ratio is what relates the NMR decay to the pore scale properties. In general, materials with larger pore spaces have longer $T_{2}$ relaxation times (e.g. gravels) and materials with smaller pores have shorter $T_{2}$ (e.g. clays). When high-quality data are acquired, such as with downhole systems, the $T_{2}$ relaxation times can be fit using multi-exponential decay curves. The distribution of decay times represents the properties of all the pores within the excited volume. We acquired downhole NMR measurements at $0.25 \mathrm{~m}$ depth intervals down a $7.5 \mathrm{~m}$ drill hole using a Dart system (Vista Clara). The Dart quantifies water content and $T_{2}$ decay times in two cylindrical shells of varying radii $(12.7$ and $15.2 \mathrm{~cm}$ ) within the drill hole.

\subsection{Transient electromagnetics (TEM)}

The transient electromagnetic method utilizes a transmitting and receiving loop lying on the earth's surface. The TEM method specifically uses a short-transmitted pulse duration and measures the decay amplitude of the vertical component of the electromagnetic field generated by secondary currents as a function of time. The magnitude and decay rate of the vertical electromagnetic field is related to the electrical conductivity of the subsurface beneath the loop. The penetration depth of the method depends on the underlying conductivity 
structure and the size of the transmitting loop and the amplitude of the transmitted signal. For a more thorough description of the TEM technique, see Telford et al. (1990), Parasnis (1986), or Reynolds (2011).

We collected the TEM data using a Zonge Engineering NanoTEM system. The NanoTEM is a low-power, fast-sampling TEM system that was specifically designed to provide high-resolution images of the near surface ( $~$ $50 \mathrm{~m}$ depth). The NanoTEM data were collected using a $20 \mathrm{~m} \times 20 \mathrm{~m}$ square transmitter loop with a $5 \mathrm{~m} \times 5 \mathrm{~m}$, single-turn receiving loop. The transmitter coil had an output current of $2 \mathrm{~A}$ and a turnoff of $\sim 2 \mu$ s. The receiving loop sampled at $625 \mathrm{kHz}$, stacking 256 cycles at a repetition rate of $32 \mathrm{~Hz}$. The stacks were averaged and then inspected to remove noisy data in the late times. The NanoTEM data were inverted using the Aarhusinv program, run using "smooth model" settings (Auken et al., 2006, 2015). The 1D inversion assumes laterally homogeneous layers. All NanoTEM soundings were inverted separately (i.e. there were no lateral constraints) and placed next to one another and interpolated to generate pseudo $2 \mathrm{D}$ profiles of bulk electrical conductivity. The quality of the inversion is determined by a misfit value between the observed and modelled voltages.

\subsection{Drill hole soil sample measurements}

Soil samples were collected at $0.25 \mathrm{~m}$ intervals from the continuous core that was retrieved during the shallow drilling programme. Each soil sample was placed into an airtight plastic container to prevent moisture loss and preserved for later analysis in the laboratory for gravimetric water contents and soil pore water salinity. The gravimetric water content was determined as the water loss between the wet and dry sample after $3 \mathrm{~d}$ in an oven at $40^{\circ}$, using standard methodologies as described in Rayment and Higginson (1992). Salinity (i.e. electrical conductivity) of the pore water was measured using a $1: 5$ mass ratio by combining $20 \mathrm{~g}$ of soil and $100 \mathrm{~g}$ of ultra-pure water (He et al., 2012, p. 5; Rayment and Higginson, 1992). The samples were agitated by rotating in a tumbler device for $48 \mathrm{~h}$ and left to settle for $1 \mathrm{~h}$, and then an electrical conductivity probe was used to measure the electrical conductivity of the supernatant. The soil water conductivity was determined using the $1: 5$ ratio dilution factor. For the shallow drill hole, we have gravimetric water content and soil conductivity as a function of depth. To make comparisons with the NMR data, the gravimetric water content was converted into volumetric water content by multiplying an assumed soil density between 1.3 and $1.5 \mathrm{~g} \mathrm{~cm}^{-3}$. We also assumed the density of water equal to $1 \mathrm{~g} \mathrm{~cm}^{-3}$.
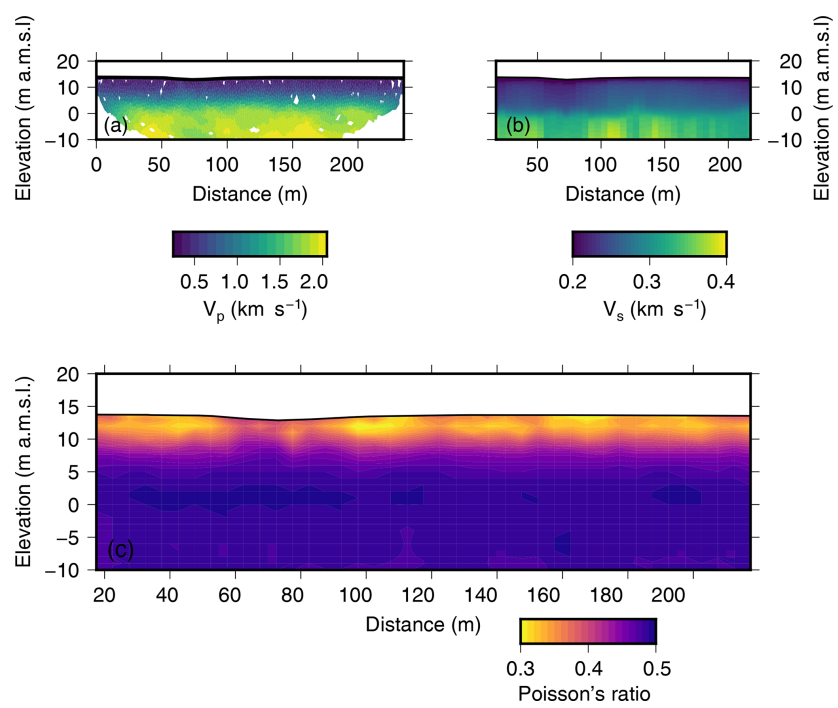

Figure 2. (a) The $\mathrm{P}$-wave velocity results shown at $2 \times$ vertical exaggeration. Areas where no rays pass through a model cell have been masked out. (b) The S-wave velocity results shown at $2 \times$ vertical exaggeration. This image shows the $421 \mathrm{D}$ inversions side by side; no interpolation has been applied. (c) Profile of Poisson's ratio calculated using Eq. (1) and the profiles shown in (a) and (b).

\section{Results}

\subsection{Seismic results}

We use the P-wave profile generated by travel-time tomography (Fig. 2a) and the S-wave profile estimated through the inversion of surface waves (Fig. 2b) to create a Poisson's ratio profile (Eq. 1) (Fig. 2c). Under the assumption that changes in Poison's ratio are due to saturation and not changes in lithology, Poisson's ratio should increase to values close to 0.5 as saturation approaches $100 \%$. In our data, Poisson's ratio increases with depth and averages out to a value of $\sim 0.46$ below an elevation of $5 \mathrm{~m}$ a.m.s.l. (Fig. $2 \mathrm{c}$ ). An anomaly occurs between 60 to $80 \mathrm{~m}$ along the profile and is the only location where high Poisson's ratios $(>0.4)$ reach the surface. This observation is not surprising given that this profile is driven by $\mathrm{P}$-wave and $\mathrm{S}$-wave profiles where at 60 $80 \mathrm{~m}$ along the profile we observed a drop in S-wave velocities, while the P-wave velocities increased slightly (Fig. 2a and $\mathrm{b}$ ). Because the difference in $\mathrm{P}$-wave and S-wave velocity is larger, Poisson's ratio is also larger (Eq. 1).

The P-wave velocity profile is characterized by two features. The first feature is a laterally homogeneous layer defined by a consistent increase in velocity from about 0.3 to $1.5 \mathrm{~km} \mathrm{~s}^{-1}$. The bottom of the feature is defined by a velocity of $\sim 1.5 \mathrm{~km} \mathrm{~s}^{-1}$ and corresponds to the depth where the vertical velocity gradient weakens significantly (Fig. S3d). This boundary, which is clearly identified in the travel-time picks (Fig. S2), defines the bottom of an approximately $13 \mathrm{~m}$ thick horizontal layer at around $0 \mathrm{~m}$ elevation (Fig. 2a). The second 
feature is more subtle and is associated with a change in slope in the travel-time picks between 60 and $80 \mathrm{~m}$ (Fig. S2a). Because of the high quality of the seismic data, the inversion was able to adjust this change in slope in the traveltime curves (Fig. S2), which is reflected in the final model (Fig. 2a).

Like the P-wave velocity profile, the $\mathrm{S}$-wave profile is laterally continuous (Fig. 2b). On average the S-wave velocity increases from $0.2 \mathrm{~km} \mathrm{~s}^{-1}$ at the surface to $0.4 \mathrm{~km} \mathrm{~s}^{-1}$ in the deepest parts of the model. There is an abrupt increase in velocity around $0 \mathrm{~m}$ elevation (Fig. $2 \mathrm{~b}$ ), which is consistent with the large change in velocity observed in the P-wave velocity profile (Fig. 2a). There is one notable difference between the two profiles occurring between 60 and $80 \mathrm{~m}$, approximately at the same location where we observed the subtle increase in P-wave velocities; unlike the P-wave velocities, the S-wave velocities are defined by a slight decrease in velocity (Fig. 2b), which was also a clear and observable feature in the picked dispersion curves (Fig. S4).

\subsection{TEM results}

The 26 NanoTEM soundings show consistency between the soundings (Fig. 3a). To ease comparisons to both the $\mathrm{S}$-wave and $\mathrm{P}$-wave profiles, the soundings were interpolated to a $2.5 \mathrm{~m} \times 0.5 \mathrm{~m}$ grid. In this grid the distance along the $x$ axis is relative to the start of the seismic profile (Fig. 1). The interpolation was done using an adjustable tension continuous curvature spline (Smith and Wessel, 1990). In the interpolated section (Fig. 3b), the most resistive feature $\left(<200 \mathrm{mS} \mathrm{m}^{-1}\right)$ occurs at the ground surface and extends to an elevation of $10 \mathrm{~m}$ a.m.s.l. (above mean sea level) between 60 and $80 \mathrm{~m}$ along the profile. The resistive feature is well constrained by individual soundings (Fig. 3a) and extends both laterally and at depth on both sides of the depression between 10 and $5 \mathrm{~m}$ a.m.s.l. and from 40 to $160 \mathrm{~m}$ along the profile (Fig. 3b).

\subsection{NMR and soil sample results}

The downhole NMR results show that the volumetric water contents of the soil profile vary between 0 and $0.25 \mathrm{~m}^{3} \mathrm{~m}^{-3}$, with a gradual increase with depth (Fig. 4a). The maximum water content of $0.25 \mathrm{~m}^{3} \mathrm{~m}^{-3}$ was measured between 6.75 and $7 \mathrm{~m}$ depth, consistent with the measured water level depth $(6.8 \mathrm{~m})$ (Fig. 4a). The average amplitude of the noise in the water contents determined by NMR is $\sim 0.05 \mathrm{~m}^{3} \mathrm{~m}^{-3}$. Therefore, inverted water contents of less than $0.05 \mathrm{~m}^{3} \mathrm{~m}^{-3}$ are less reliable. Signals from the soundings can be found in the Supplement (Fig. S6). Above the water table, the NMR data showed a rise in water contents above $0.05 \mathrm{~m}^{3} \mathrm{~m}^{-3}$ between 1.75 and $3 \mathrm{~m}$ depth. The water within this region contains low $T_{2}$ relaxation times $(<0.01 \mathrm{~s})$. A similar pattern in water content and $T_{2}$ decay times occurs between 4 and $6 \mathrm{~m}$ depth (Fig. 4a and b). Around $6 \mathrm{~m}$ depth the $T_{2}$ distributions transition from shorter to longer $(>0.01 \mathrm{~s})$ relaxation times

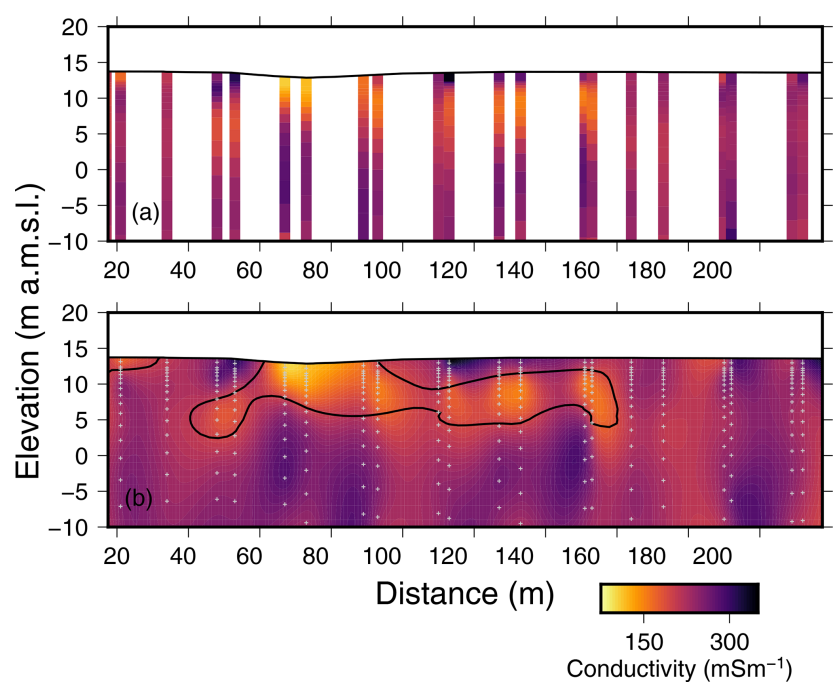

Figure 3. Electrical conductivity results produced by the NanoTEM soundings. The $x$ axis is distance from the first geophone (Fig. 1). Both panels are shown at $2 \times$ vertical exaggeration. (a) Onedimensional conductivity profiles plotted at their inverted resolutions as well as their spatial locations. (b) The interpolated conductivity section. The black contour represents $200 \mathrm{mS} \mathrm{m}^{-1}$. The small grey plus symbols represent the data used for the interpolation.

and the water contents also increase (Fig. 4b). This gradual increase in the $T^{2}$ decay times and water content is likely to be the capillary fringe, where the remaining pore space fills from smallest to largest pores. At depths below the measured water level $(6.8 \mathrm{~m})$, the $T_{2}$ distributions normalize and have a value just over $0.01 \mathrm{~s}$, which is consistent with clays.

The gravimetric water content measured from the drill hole core samples had an average of 0.15 with a standard deviation of 0.02 and showed very little variation with depth (Fig. 4c). The soil pore water conductivity also showed little variation with depth, having an average conductivity of $1123 \mu \mathrm{S} \mathrm{cm}^{-1}$ with a standard deviation of $424 \mu \mathrm{S} \mathrm{cm}^{-1}$ (Fig. 4c). When converted to $\mathrm{mS} \mathrm{m}^{-1}$ (112.3 \pm $\left.42.5 \mathrm{mS} \mathrm{m}^{-1}\right)$ the soil conductivities are in within the range of conductivities observed in the TEM profile. In contrast to soil conductivities, the measured groundwater conductivity was $14750 \mu \mathrm{S} \mathrm{cm}^{-1}$ (conductivity of sea water is $\sim$ $50000 \mu \mathrm{S} \mathrm{cm}^{-1}$ ). The TEM conductivity represents an average between the soil conductivity and groundwater conductivity, which is why we do not observe high conductivity values below the water table (Fig. 3). There is also notable difference in the gravimetric water contents and NMR water contents (Fig. 3). This difference could be attributed to the fact that the NMR cannot detect water in the smallest pores. Below the water table, where the assumption of fully saturated pores is likely satisfied, the gravimetric water contents and NMR water contents are in much closer agreement (Fig. 4a). 


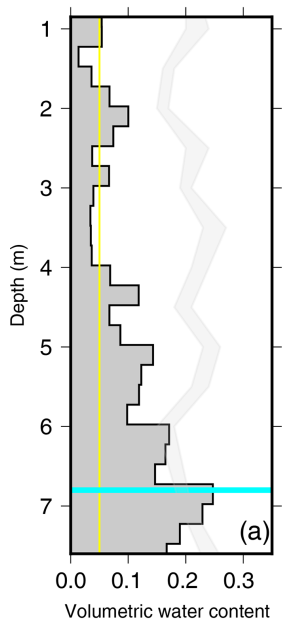

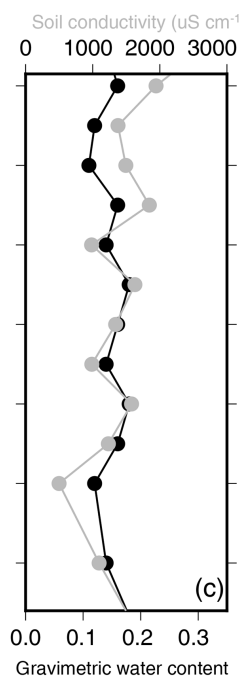

Figure 4. Results from the downhole NMR sounding and soil samples at the drill hole location versus depth (metres below ground level; Fig. 1). (a) The water content profile from the downhole NMR data. The thin vertical yellow line shows the average noise level $\left(0.05 \mathrm{~m}^{3} \mathrm{~m}^{-3}\right)$ below which water content estimates are questionable. The thick horizontal cyan line represents the manually measured water level from ground surface $(6.8 \mathrm{~m})$. The thin transparent region is the volumetric water content estimated from the measured gravimetric water content, assuming a soil density between 1.3 and $1.5 \mathrm{~g} \mathrm{~cm}^{3}$. (b) The $T_{2}$ distributions that produced the water content curves in (a). The maximum water contents are calculated by summing the area under the distribution. (c) Soil conductivity (grey) and gravimetric water contents (black) as a function of depth.

\section{Discussion}

\subsection{Geophysically inferred water table depth}

To estimate a value of Poisson's ratio that represents the water table, we laterally averaged two regions along the profile to produce two 1D profiles with standard deviations. The standard deviations represent the lateral variability. The first laterally averaged region was between 60 and $80 \mathrm{~m}$, where the large anomaly occurs and where higher values of Poisson's ratio reach the surface (Fig. 5a). The second region was chosen to be from 120 to $220 \mathrm{~m}$ because qualitatively it appears laterally uniform and includes the drill hole location (drill hole located at $220 \mathrm{~m}$ ). These two averaged 1D profiles, when plotted side by side, show a similar trend in increasing Poisson's ratio (Fig. 5c) but present a clear offset. Near the surface the difference is largest, but the two curves begin to converge near the water level measurement of $6.8 \mathrm{~m}$ depth below ground and the highest water contents from the NMR (Fig. 5c). At the inferred water table, the values of Poisson's ratio between 60-80 and 120-220 m are $0.454 \pm 0.004$ and $0.475 \pm 0.002$, respectively (Fig. 5b). Here we use a value of 0.46 as the contour that represents the water table, which we refer to as the geophysically in- ferred water table depth. The value of 0.45 also validated against the manual water level measurements $(6.8 \mathrm{~m}$ depth below ground) and the downhole NMR water content profile from the drill hole (occurring at $220 \mathrm{~m}$ along the profile). It also corresponds well with previous values given by Pasquet et al. (2015a, b).

Under the assumption of a flat water table from the drill hole, the contour value of 0.46 matches qualitatively the depth to water between 0 and $60 \mathrm{~m}$ and again between 80 and $220 \mathrm{~m}$ (Fig. 5a). There is one notable deviation occurring between 60 and $80 \mathrm{~m}$ where we highlight anomalies in all three geophysical methods. We observed a slight increase in P-wave velocities (Fig. 2a), slightly lower S-wave velocities (Fig. 2b), and a resistive feature in the NanoTEM data (Fig. 3). As a result, the geophysically inferred water table depth at this location along the profile differs from the manually measured water level (Fig. 5a). We interpret this rise in Poisson's ratios as the water table rising toward the surface beneath the subtle topographic depression in the landscape, representing the ephemeral drainage feature (Fig. 5b).

Using a contour value of 0.46 provides an estimate for the water table, but the boundary is fuzzy and possibly transitional (Fig. 5a). The fuzziness of the boundary could be explained by two processes. First, partial saturation could be occurring above the water table. Second, the water table boundary could be well defined, but it is smoothed over by the geophysical inversions. The smoothing is difficult to quantify and is complicated by the fact that the P-wave and $S$-wave velocities come from two different inversions based on different physics. More research is needed to understand and compare the sample volumes of the travel-time tomography and surface wave inversions. The first interpretation of a transitional zone between unsaturated and saturated sediments is more likely because of observations in the NMR data (Fig. 4) and the presence of water measured in the collected soil samples (Fig. 5c).

In the downhole NMR data, we are confident with measured water contents greater than $0.05 \mathrm{~m}^{3} \mathrm{~m}^{-3}$. At $4 \mathrm{~m}$ depth the water content is well above $0.05 \mathrm{~m}^{3} \mathrm{~m}^{-3}$ and shows a linear increase until a maximum value of $0.25 \mathrm{~m}^{3} \mathrm{~m}^{-3}$ is reached between 6.75 and $7.0 \mathrm{~m}$ below the surface (Fig. 4). Below the water table, the maximum water content likely represents total porosity. All the NMR responses above the water table have low $T_{2}$ decay times (Fig. 4b), which can either be indicative of clay or caused by small pores, which preferentially fill and hold water after being drained (i.e. leading to partial saturation of the medium) (Walsh et al., 2014). The preferentially filled pores seems more likely because we know that the measurements were made within the vadose zone, and the measured gravimetric water contents of the drill hole core showed that samples retained some moisture. The most important observation provided by the NMR data is that partially saturated sediments exist at least $3 \mathrm{~m}$ above the water table (Fig. 5c). This partially saturated region of the soil profile will likely increase Poisson's ratios 

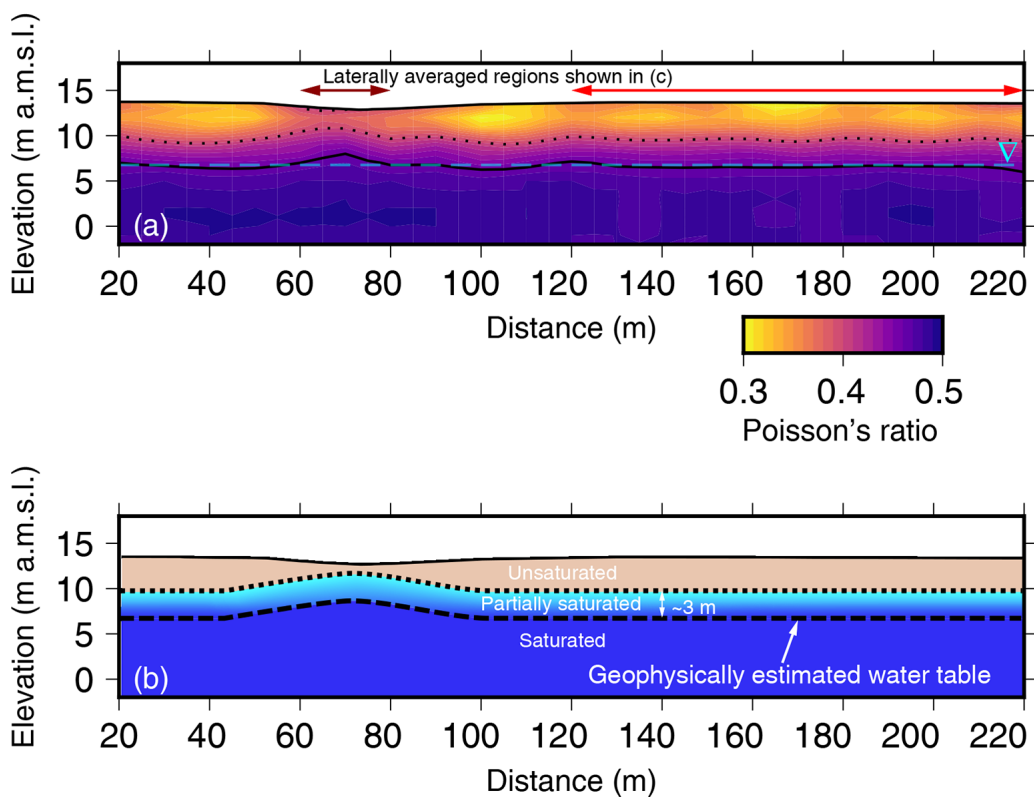

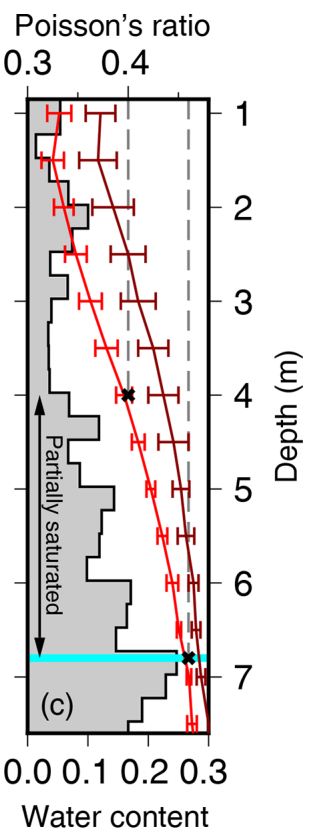

Figure 5. (a) Profile of Poisson's ratio calculated using Eq. (1) and the profiles shown in Figs. 2 and 3. The solid black contour represents a Poisson's ratio of 0.46 . The dashed cyan line is the depth of water measured at the drill hole located at $220 \mathrm{~m}(6.8 \mathrm{~m}$ b.g.s. - below ground surface) and extends horizontally across the profile to be able to visualize the changes beneath the ephemeral feature. The dotted contour line is the 0.4 contour line, which is consistent with a $3 \mathrm{~m}$ thick partially saturated region. (b) Geophysically interpreted hydrogeological cross section. The unsaturated zone is quantified by areas with Poisson's ratios less than 0.40 . The partially saturated region, with a thickness of approximately $3 \mathrm{~m}$ (determined from NMR in c), has Poisson's ratios between 0.4 and 0.46 . The fully saturated region has Poisson's ratios greater than 0.46 . The geophysically inferred water table is approximated by the 0.46 contour in (a). (c) The water content profile from Fig. 4 . The partially saturated region from 4 to $6.8 \mathrm{~m}$ depth is highlighted. The horizontal cyan bar is the manual water level measurement (6.8 m). Overlain on the water content profile are the two horizontally averaged 1D Poisson's ratio profiles. The red line is averaged from 120 to $220 \mathrm{~m}$ and the maroon line is averaged between 60 and $80 \mathrm{~m}$ along the profile. Black dashed lines and solid crosses highlight the Poisson's ratio contour values of 0.4 and 0.46 chosen in (a).

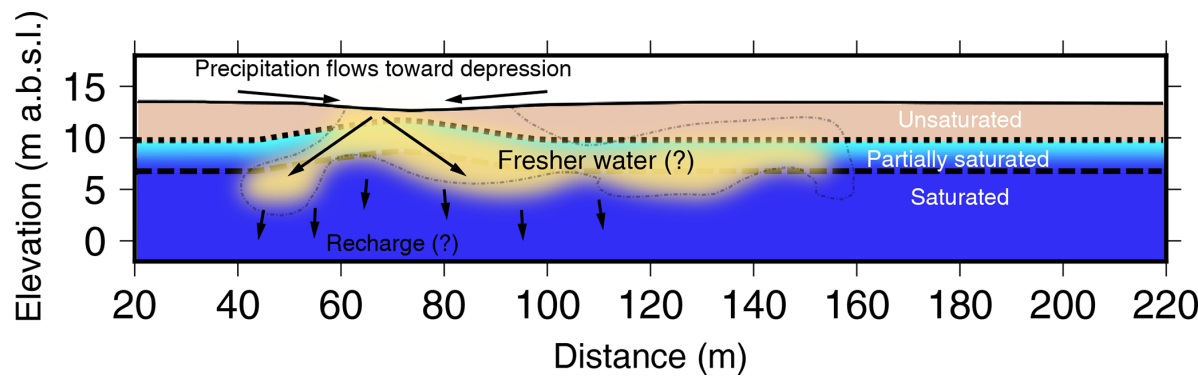

Figure 6. The final hydrogeological framework for a subtle ephemeral surface water feature in the semi-arid landscape of the Northern Adelaide Plains. The underlying map is based on the seismic data. The yellow region is our interpreted region of fresher water that has recharged the shallow unconfined aquifer system. Here water flows across the land surface and collects into the subtle ephemeral drainage feature. From there water is recharged into the underlying aquifer system and the hydraulic gradient drives recharging water away from the groundwater mound, to either side. During the recharge process, the fresher recharge water is mixing with the ambient saline groundwater of the shallow Quaternary aquifer.

and provides an explanation for the transitional and fuzzy boundary we observe in the seismic data. Furthermore, if the 0.46 contour is shifted upward $3 \mathrm{~m}$ based on the NMR observation, it qualitatively matches the point where Poisson's ratio begins to increase (Fig. 5a). From the combined inter- pretation of seismic data, manual water level measurement, and NMR data, we are therefore able to identify a mound in the water table underneath the small topographic depression, existing between 60 and $80 \mathrm{~m}$ along the profile (Fig. 5b). The NMR data and Poisson's ratio suggest the existence of a 
$\sim 3 \mathrm{~m}$ thick section of partially saturated sediments on top of the water table along the profile (Fig. 5b).

\subsection{Geophysically identified recharge processes}

In the previous section we relied heavily on the seismic data, NMR data, soil cores, and water level to define a geophysically inferred water table depth along the study transect (Fig. 5b). We argued for the existence of a $3 \mathrm{~m}$ thick partially saturated region above the water table based on water contents from the NMR data (Figure 5c). In this section we utilize the bulk electrical conductivities obtained from the NanoTEM data to strengthen the interpretation that the Poisson's ratio anomaly between 60 to $80 \mathrm{~m}$ along the transect is caused by an increase in saturation to demonstrate that the subtle topographic surface depression acts as a localized recharge zone.

Ambiguities exist in geophysical measurements because they measure physical properties that are related to the processes that we are trying to understand. Although we do not expect any lithological variation based on the known soil and geological mapping of the area, it is possible that the region of high Poisson's ratios is a result of higher clay content, since materials that are deformed easily will have higher Poisson's ratios. Poisson's ratio for pure quartz, a stiff mineral, is between 0.06 and 0.08 , Kaolinite is 0.14 , and clays are around 0.34 and 0.35 (Mavko et al., 2009). It would be reasonable to assume higher clay content as an alternative interpretation to explain the higher Poisson's ratios under the topographic surface depression. Here the conductivities from the NanoTEM provide evidence to suggest that an increase in clay content is unlikely. If the high Poisson's ratio were due to an increased clay content, we would expect the electrical conductivities to rise - but we observe the opposite. The subsurface is more resistive at the location where Poisson's ratios rise.

Underneath the small depression in topography between 60 and $80 \mathrm{~m}$ along the seismic profile we have anomalies in all three geophysical data sets: (1) the P-wave velocities increase, (2) the S-wave velocities decrease, and (3) the electrical conductivities decrease. As discussed in the previous section, the first two anomalies cause Poisson's ratio to rise, which we interpret as a rise in the water table or at a minimum increase in water saturation. Here we believe the decrease in electrical conductivity is the result of more conductive groundwater being replaced by fresher water that has infiltrated from rainfall events. Although we did not measure the electrical conductivity of rainwater, we know that the groundwater from the shallow aquifer at the study site has a much higher conductivity $\left(14750 \mu \mathrm{S} \mathrm{cm}^{-1}\right)$ which is similar to observed salinities in the shallow Quaternary system across the NAP, which range between 2000 and $13000 \mathrm{mg} \mathrm{L}^{-1}$ (3075 to $20000 \mu \mathrm{S} \mathrm{cm}^{-1}$ ) (Department for Water, 2010). Typically, an increase in saturation causes an increase in electrical conductivity. A simplified and general modelling exercise using Archie's Law shows that if we replace the water in the pores with a more resistive fluid, it is possible to get a drop in electrical conductivity even if the saturation is increased (refer to Supplement). Thus the decrease in electrical conductivity supports the interpretation that the rise in Poisson's ratios is caused by an increase in water content and not an increase in clay content.

\subsection{Hydrogeological implications}

We combine all the geophysical observations to construct a hydrogeological interpretation of the study site (Fig. 6). First, based on the seismic data and the measured water depth from the nearby drill hole we can identify a rise in the water table beneath the small topographic depression. It is likely that this rise in water table has a partially saturated region that is $\sim 3 \mathrm{~m}$ thick above it. Because of the observed drop in electrical conductivities, we interpret this feature as a saturation increase and not a change due to an increase in clay content. We interpret the drop in electrical conductivities as fresher water diluting and mixing with the ambient saline groundwater of the Quaternary aquifer. The resistive feature lies above the partially saturated or saturated zones between 80 and $100 \mathrm{~m}$ and again between 120 and $140 \mathrm{~m}$ (Fig. 6).

Our study has shown that the smaller tributaries and ephemeral streams across the lower-lying areas of the NAP are acting as localized sources for recharge to the Quaternary and Tertiary aquifers. This suggests that there is localized areas of recharge across the NAP associated with these types of subtle features - an interpretation that is consistent with the findings of Bresciani et al. (2018), which showed that the main recharge mechanisms to the Quaternary and Tertiary aquifer systems across the NAP was through surface water infiltration along the large river systems (e.g. the Gawler and Little Para rivers) that have their headwaters in the Mount Lofty Ranges and outlets towards the coast.

It should be noted that our hydrogeological interpretation is based on a single snapshot in time. Without time-lapse geophysical measurements, groundwater samples taken from within the groundwater mound and either side, or long-term monitoring of groundwater observation wells, it is not possible to definitively quantify the recharge rates in these systems. Nor is it possible to determine whether the groundwater mound is a result of a recent rainfall event or whether it is a more stable feature. It seems reasonable, given the evidence of ephemeral surface drainage features in the lidar data (Fig. 1) and the high clay content of the near subsurface that surface water would flow towards subtle depressions in the landscape and eventually out to St Vincent Gulf (Fig. 6). These small ephemeral features are unmonitored, so it is unknown how quickly or how much water flows through them during storm events. The NAP are topographically flat so it is possible that instead of surface water flowing out towards the ocean, water might accumulate in these low-lying features after large rainfall or storm events and gradually infiltrate over 
longer periods of time. The ponded water from such rainfall events would produce localized recharge to the underlying aquifer system (Fig. 6). The recharge water would be fresher than the groundwater already in the Quaternary aquifer system.

The hydrological conceptualization based on the geophysical data (Fig. 6) could be confirmed or rejected by drilling and sampling the groundwater via an additional shallow drill hole across the shallow topographic depression. The combination of geophysical data has provided a new perspective that allows us to speculate about important local hydrological processes taking place in the NAP. Furthermore, the combined geophysical approach presented here can be used to guide and plan more widespread investigations focused on understanding the role of these subtle ephemeral features across this flat semi-arid landscape. The combined geophysical approach provided a vital conceptual framework for the hydrological processes occurring within the area. Future work should focus on combining the geophysical measurements with more traditional hydrological and geochemical measurements to fully explore and test the hydrogeological conceptualization suggested in this paper and the transient nature of the recharge mechanisms (Fig. 6).

\subsection{Applying the combined geophysical approach to other semi-arid regions}

Throughout this study we used well-established geophysical methods. Each of these methods have open-source inversions available or the equipment comes with easy-to-use inversion software. Thus, there is nothing novel about the processing of each individual geophysical data set, but the combination of all these methods can be used to rapidly explore flat-lying features to test a given conceptual model of the recharge processes in a flat-lying semi-arid landscape. In order to facilitate and expand the use of this combined geophysical approach to other semi-arid streams or features, we highlight some of the uncertainty, limitations, advantages, and critical assumptions that went into building the hydrological conceptualization so that this methodology might be transferred to other semi-arid areas that are common around the world.

We relied heavily on the manual water level measurement and downhole NMR data. The geophysical mapped water table essentially extended from the water level that we were able to measure at the drill hole location. The drill hole data were critical to calibrate the value of Poisson's ratio that we used to represent the water table. The method would be much more powerful if the drill hole was not required, but because this was the first survey of its kind in the region we needed to confirm where the water level was to interpret Poisson's ratio. Now, with a value of 0.45 it would be possible to run a survey without the drill hole and predict the water level without a drill hole. Thus, some validation is required prior to extending the methodologies throughout the NAP.
The NAP provided ideal conditions for us to exploit Poisson's ratio to map the water table in detail. The NAP were ideal because the subsurface was broadly homogeneous, and there were no abrupt or lateral variations in the lithology. Lithological variation would complicate the interpretation of Poisson's ratio because all the changes could not be attributed solely to changes in saturation. We were also specific in selecting a location where the water table was between 3 and $10 \mathrm{~m}$ depth. In order to image the saturated zone with seismic methodologies, we required an elastic contrast between the unsaturated and saturated zones. Although uncertainty is difficult to quantify given the different sample volumes and wavelengths of the seismic wave field and Rayleigh waves (work that extends beyond the scope of this paper), we believe that having at least $3 \mathrm{~m}$ of unsaturated zone above the water table should provide a strong enough contrast to image. Furthermore, the inversion of surface waves is limited by the frequency content of the source and the peak geophone frequency. In our case, with $14 \mathrm{~Hz}$ geophones, imaging a water table that is below $\sim 10-12$ m would be difficult. Thus, to improve chances of success, the seismic approach should be applied in regions where the water table is between 3 and $10 \mathrm{~m}$ in a homogeneous material. We used the existing 47 boreholes from another study (Hatch et al., 2019) to select a site that satisfied this condition.

The additional information provided by the NanoTEM data helped reduce ambiguities observed in the Poisson's ratio profile. Without this additional information it would have been difficult to determine whether the anomaly was caused by an increased clay content or an increase in water content. Thus, the electrical conductivity data were critical to our hydrological interpretation. It should be noted that the NanoTEM data could also be replaced by another independent observation, e.g. other near-surface geophysical methods or soil conductivity profiles at several locations along the transect. Regardless, more observational evidence, even if they are point measurements, will aid in the interpretation of the geophysical images.

\section{Conclusions}

We have shown that the combination of P-wave and S-wave velocities, electrical conductivities, and surface NMR can identify small-scale ephemeral recharge features in a semiarid landscape without the use of time-lapse measurements. The seismic data were used to calculate Poisson's ratio and served as the foundation to geophysically infer the water table depth. The NMR data showed a $3 \mathrm{~m}$ thick region of partially saturated sediments, and the electrical conductivities from the NanoTEM provided additional evidence to support an increase in water content opposed to an increase in clay content. The combination of all four data sets has provided a hydrogeological framework where we are observing fresher water recharging and replenishing the underlying saline Qua- 
ternary aquifer system. Although the timing or flux rates of the recharge cannot be determined with our data, we have shown that small-scale ephemeral features could play a vital role in recharge mechanisms to the shallow unconfined aquifers of the low-lying semi-arid landscape of the North Adelaide Plains. The interpretation of the geophysical data still requires more traditional hydrogeological measurements to completely validate the results, but we have demonstrated that the spatially exhaustive perspective gained, using nearsurface geophysical methods, can be valuable to understanding the recharge processes and conceptualization of semiarid hydrological systems.

Data availability. Data sets are available at https://doi.org/10.25919/5dcc9dedd8a67 (Flinchum, 2019), http://www.hydroshare.org/resource/ 6a918b747dd64eeb9ae891d697f0e42d (last access: $27 \mathrm{Au}-$ gust 2020) (Flinchum, 2020a), and http://www.hydroshare.org/ resource/6baf60ed02b84e488dfe8d0b8b0f7046 (last access: 27 August 2020) (Flinchum, 2020b).

Supplement. The supplement related to this article is available online at: https://doi.org/10.5194/hess-24-4353-2020-supplement.

Author contributions. BAF, EB, OB, and $\mathrm{MH}$ all contributed to the design of the study. BAF, EB, and MH collected and processed all data presented in the paper. BAF, EB, MH, LJMP, and OB all contributed to writing the original draft and reviewing and editing the final submission. SP validated the S-wave inversions and contributed to reviewing and editing the manuscript.

Competing interests. The authors declare that they have no conflict of interest.

Acknowledgements. We would like to thank Adrian Costar for help in collection of the seismic data set. We acknowledge funding from the Goyder Institute for Water Research for the project ED-1701, "Sustainable expansion of irrigated agriculture and horticulture in Northern Adelaide Corridor: Task 4 - assessment of depth to groundwater (proof of concept)". We are grateful for the land access provided by John Gordon. We would also like to thank Chris Li and Sebastian Lamontagne for providing valuable comments that improved the paper. We would also like to thank Alan MacDonald and Kent Inverarity for taking the time to review this paper and provide comments that helped improve the overall clarity of the paper.

Financial support. This research has been supported by the Goyder Institute for Water Research (grant no. ED-17-01) and the CSIRO's Deep Earth Imaging Future Science Platform.
Review statement. This paper was edited by Ty P. A. Ferre and reviewed by Alan MacDonald and Kent Inverarity.

\section{References}

Abdulrazzak, M. J.: Losses of flood water from alluvial channels, Arid Soil Res. Rehab., 9, 15-24, https://doi.org/10.1080/15324989509385870, 1995.

Acuña, V., Datry, T., Marshall, J., Barceló, D., Dahm, C. N., Ginebreda, A., McGregor, G., Sabater, S., Tockner, K., and Palmer, M. A.: Why Should We Care About Temporary Waterways?, Science, 343, 1080-1081, https://doi.org/10.1126/science.1246666, 2014.

Allison, G. B., Cook, P. G., Barnett, S. R., Walker, G. R., Jolly, I. D., and Hughes, M. W.: Land clearance and river salinisation in the western Murray Basin, Australia, J. Hydrol., 119, 1-20, https://doi.org/10.1016/0022-1694(90)90030-2, 1990.

Anderson, T. A., Bestland, E. A., Wallis, I., and Guan, H. D.: Salinity balance and historical flushing quantified in a high-rainfall catchment (Mount Lofty Ranges, South Australia), Hydrogeol. J., 27, 1229-1244, https://doi.org/10.1007/s10040-018-01916-7, 2019.

Auken, E., Pellerin, L., Christensen, N. B., and Sørensen, K.: A survey of current trends in near-surface electrical and electromagnetic methods, Geophysics, 71, G249-G260, https://doi.org/10.1190/1.2335575, 2006.

Auken, E., Christiansen, A. V., Kirkegaard, C., Fiandaca, G., Schamper, C., Behroozmand, A. A., Binley, A., Nielsen, E., Effersø, F., Christensen, N. B., Sørensen, K., Foged, N., and Vignoli, G.: An overview of a highly versatile forward and stable inverse algorithm for airborne, ground-based and borehole electromagnetic and electric data, Explor. Geophys., 46, 223-235, https://doi.org/10.1071/EG13097, 2015.

Bachrach, R. and Nur, A.: High-resolution shallow-seismic experiments in sand, Part I: Water table, fluid flow, and saturation, Geophysics, 63, 1225-1233, https://doi.org/10.1190/1.1444423, 1998.

Bachrach, R., Dvorkin, J., and Nur, A.: Seismic velocities and Poisson's ratio of shallow unconsolidated sands, Geophysics, 65, 559-564, https://doi.org/10.1190/1.1444751, 2000.

Banks, E. W., Simmons, C. T., Love, A. J., Cranswick, R., Werner, A. D., Bestland, E. A., Wood, M., and Wilson, T.: Fractured bedrock and saprolite hydrogeologic controls on groundwater/surface-water interaction: a conceptual model (Australia), Hydrogeol. J., 17, 1969-1989, https://doi.org/10.1007/s10040-009-0490-7, 2009.

Banks, E. W., Simmons, C. T., Love, A. J., and Shand, P.: Assessing spatial and temporal connectivity between surface water and groundwater in a regional catchment: Implications for regional scale water quantity and quality, J. Hydrol., 404, 30-49, https://doi.org/10.1016/j.jhydrol.2011.04.017, 2011.

Batlle-Aguilar, J., Banks, E. W., Batelaan, O., Kipfer, R., Brennwald, M. S., and Cook, P. G.: Groundwater residence time and aquifer recharge in multilayered, semi-confined and faulted aquifer systems using environmental tracers, J. Hydrol., 546, 150-165, https://doi.org/10.1016/j.jhydrol.2016.12.036, 2017.

Behroozmand, A. A., Keating, K., and Auken, E.: A Review of the Principles and Applications of the NMR Technique 
for Near-Surface Characterization, Surv. Geophys., 36, 27-85, https://doi.org/10.1007/s10712-014-9304-0, 2015.

Berryman, J. G., Berge, P. A., and Bonner, B. P.: Estimating rock porosity and fluid saturation using only seismic velocities, Geophysics, 67, 391-404, https://doi.org/10.1190/1.1468599, 2002.

Bertin, C. and Bourg, A. C. M.: Radon-222 and Chloride as Natural Tracers of the Infiltration of River Water into an Alluvial Aquifer in Which There Is Significant River/Groundwater Mixing, Environ. Sci. Technol., 28, 794-798, https://doi.org/10.1021/es00054a008, 1994.

Bloch, F.: Nuclear Induction, Phys. Rev., 70, 460-474, https://doi.org/10.1103/PhysRev.70.460, 1946.

Bresciani, E., Cranswick, R. H., Banks, E. W., Batlle-Aguilar, J., Cook, P. G., and Batelaan, O.: Using hydraulic head, chloride and electrical conductivity data to distinguish between mountainfront and mountain-block recharge to basin aquifers, Hydrol. Earth Syst. Sci., 22, 1629-1648, https://doi.org/10.5194/hess-221629-2018, 2018.

Brownstein, K. R. and Tarr, C. E.: Importance of classical diffusion in NMR studies of water in biological cells, Phys. Rev. A, 19, 2446-2453, https://doi.org/10.1103/PhysRevA.19.2446, 1979.

Brunner, P., Simmons, C. T., and Cook, P. G.: Spatial and temporal aspects of the transition from connection to disconnection between rivers, lakes and groundwater, J. Hydrol., 376, 159-169, https://doi.org/10.1016/j.jhydrol.2009.07.023, 2009.

Carey, A. M. and Paige, G. B.: Ecological Site-Scale Hydrologic Response in a Semiarid Rangeland Watershed, Rangeland Ecol. Manage., 69, 481-490, https://doi.org/10.1016/j.rama.2016.06.007, 2016.

Chapman, T.: A comparison of algorithms for stream flow recession and baseflow separation, Hydrol. Process., 13, 701-714, https://doi.org/10.1002/(sici)10991085(19990415)13:5<701::aid-hyp774>3.0.co;2-2, 1999.

Claes, N., Paige, G. B., and Parsekian, A. D.: Uniform and lateral preferential flows under flood irrigation at field scale, Hydrol. Process., 33, 2131-2147, https://doi.org/10.1002/hyp.13461, 2019.

Coates, G. R., Xiao, L., and Prammer, M. G.: NMR logging principles and applications, Halliburton Energy Services, United States, 1999.

Cohen, M. H. and Mendelson, K. S.: Nuclear magnetic relaxation and the internal geometry of sedimentary rocks, J. Appl. Phys., 53, 1127-1135, https://doi.org/10.1063/1.330526, 1982.

Cook, P. G., Solomon, D. K., Sanford, W. E., Busenberg, E., Plummer, L. N., and Poreda, R. J.: Inferring shallow groundwater flow in saprolite and fractured rock using environmental tracers, Water Resour. Res., 32, 1501-1509, https://doi.org/10.1029/96WR00354, 1996.

Crosbie, R. S., Peeters, L. J. M., Herron, N., McVicar, T. R., and Herr, A.: Estimating groundwater recharge and its associated uncertainty: Use of regression kriging and the chloride mass balance method, J. Hydrol., 561, 1063-1080, https://doi.org/10.1016/j.jhydrol.2017.08.003, 2018.

Cuthbert, M. O., Acworth, R. I., Andersen, M. S., Larsen, J. R., McCallum, A. M., Rau, G. C., and Tellam, J. H.: Understanding and quantifying focused, indirect groundwater recharge from ephemeral streams using water table fluctuations, Water Resour. Res., 52, 827-840, https://doi.org/10.1002/2015WR017503, 2016.
Cuthbert, M. O., Gleeson, T., Moosdorf, N., Befus, K. M., Schneider, A., Hartmann, J., and Lehner, B.: Global patterns and dynamics of climate-groundwater interactions, Nat. Clim. Change, 9, 137-141, https://doi.org/10.1038/s41558-018-0386-4, 2019.

Dahan, O., Shani, Y., Enzel, Y., Yechieli, Y., and Yakirevich, A.: Direct measurements of floodwater infiltration into shallow alluvial aquifers, J. Hydrol., 344, 157-170, https://doi.org/10.1016/j.jhydrol.2007.06.033, 2007.

Dahan, O., Tatarsky, B., Enzel, Y., Kulls, C., Seely, M., and Benito, G.: Dynamics of Flood Water Infiltration and Ground Water Recharge in Hyperarid Desert, Groundwater, 46, 450-461, https://doi.org/10.1111/j.1745-6584.2007.00414.x, 2008.

Department for Water: Northern Adelaide Plains PWA Groundwater Level and Salinity Status Report 2009-2010, Government of South Australia, Adelaide, South Australia, 2010.

Desper, D. B., Link, C. A., and Nelson, P. N.: Accurate water-table depth estimation using seismic refraction in areas of rapidly varying subsurface conditions, Near Surf. Geophys., 13, 455-467, https://doi.org/10.3997/1873-0604.2015039, 2015.

Dijkstra, E. W.: A note on two problems in connexion with graphs, Numer. Math., 1, 269-271, https://doi.org/10.1007/BF01386390, 1959.

Dunn, K. J., Bergman, D. J., and LaTorraca, G. A.: Nuclear Magnetic Resonance: Petrophysical and Logging Applications, Elsevier, Kidlington, Oxford, UK, 2002.

Dvorkin, J. and Nur, A.: Elasticity of high-porosity sandstones: Theory for two North Sea data sets, Geophysics, 61, 1363-1370, https://doi.org/10.1190/1.1444059, 1996.

Earman, S., Campbell, A. R., Phillips, F. M., and Newman, B. D.: Isotopic exchange between snow and atmospheric water vapor: Estimation of the snowmelt component of groundwater recharge in the southwestern United States, J. Geophys. Res.-Atmos., 111, D09302, https://doi.org/10.1029/2005JD006470, 2006.

Flinchum, B.: Seismic Reflection Data in the North Adelaide Plains, v1. CSIRO, Data Collection, https://doi.org/10.25919/5dcc9dedd8a67, 2019.

Flinchum, B. A.: Transient Electromagnetic Data form the North Adelaide Plains, HydroShare, available at: http://www. hydroshare.org/resource/6a918b747dd64eeb9ae891d697f0e42d (last access: August 2020), 2020a.

Flinchum, B. A.: Downhole Nuclear Magnetic Resonance in the North Adelaide Plains, South Australia, HydroShare, available at: http://www.hydroshare.org/resource/ 6baf60ed02b84e488dfe8d0b8b0f7046 (last access: August 2020), 2020b.

Flinchum, B. A., Holbrook, W. S., Rempe, D., Moon, S., Riebe, C. S., Carr, B. J., Hayes, J. L., Clair, J., and Peters, M. P.: Critical Zone Structure Under a Granite Ridge Inferred From Drilling and Three-Dimensional Seismic Refraction Data, J. Geophys. Res.Earth, 123, 1317-1343, https://doi.org/10.1029/2017JF004280, 2018.

Genereux, D. P. and Hemond, H. F.: Naturally Occurring Radon 222 as a Tracer for Streamflow Generation: Steady State Methodology and Field Example, Water Resour. Res., 3065-3075, https://doi.org/10.1029/WR026i012p03065, 2010.

Gleeson, T., Wada, Y., Bierkens, M. F. P., and van Beek, L. P. H.: Water balance of global aquifers revealed by groundwater footprint, Nature, 488, 197-200, https://doi.org/10.1038/nature11295, 2012. 
Gottschalk, I. P., Hermans, T., Knight, R., Caers, J., Cameron, D. A., Regnery, J., and McCray, J. E.: Integrating non-colocated well and geophysical data to capture subsurface heterogeneity at an aquifer recharge and recovery site, J. Hydrol., 555, 407-419, https://doi.org/10.1016/j.jhydrol.2017.10.028, 2017.

Goyder Institute for Water Research: Northern Adelaide Plains Water Stocktake Technical Report, Goyder Institute for Water Research, Adelaide, South Australia, 2016.

Gregory, A. R.: Fluid saturation effects on dynamic elastic properties of sedimentary rocks, Geophysics, 41, 895-921, https://doi.org/10.1190/1.1440671, 1976.

Grunewald, E. and Knight, R.: Nonexponential decay of the surfaceNMR signal and implications for water content estimation, Geophysics, 77, EN1-EN9, https://doi.org/10.1190/geo2011-0160.1, 2012

Hashin, Z. and Shtrikman, S.: A variational approach to the theory of the elastic behaviour of multiphase materials, J. Mech. Phys. Solids, 11, 127-140, https://doi.org/10.1016/00225096(63)90060-7, 1963.

Hatch, M., Batelaan, O., Banks, E., Flinchum, B., and Hancock, M.: Sustainable expansion of irrigated agriculture and horticulture in Northern Adelaide Corridor: Task 4 - assessment of depth to groundwater (proof of concept), Technical Report Series, Goyder Institue for Water Research blackbox[CE]Please provide location of issuing organisation., 2019.

He, Y., DeSutter, T., Prunty, L., Hopkins, D., Jia, X., and Wysocki, D. A.: Evaluation of $1: 5$ soil to water extract electrical conductivity methods, Geoderma, 185-186, 12-17, https://doi.org/10.1016/j.geoderma.2012.03.022, 2012.

Hoehn, E. and Gunten, H. R. V.: Radon in groundwater: A tool to assess infiltration from surface waters to aquifers, Water Resour. Res., 25, 1795-1803, https://doi.org/10.1029/WR025i008p01795, 1989.

Johnson, T. C., Slater, L. D., Ntarlagiannis, D., Day-Lewis, F. D., and Elwaseif, M.: Monitoring groundwater-surface water interaction using time-series and time-frequency analysis of transient three-dimensional electrical resistivity changes, Water Resour. Res., 48, W07506, https://doi.org/10.1029/2012wr011893, 2012.

Kotikian, M., Parsekian, A. D., Paige, G., and Carey, A.: Observing Heterogeneous Unsaturated Flow at the Hillslope Scale Using Time-Lapse Electrical Resistivity Tomography, Vadose Zone J., 18, 1-16, https://doi.org/10.2136/vzj2018.07.0138, 2019.

Lamontagne, S., Leaney, F. W., and Herczeg, A. L.: Groundwatersurface water interactions in a large semi-arid floodplain: implications for salinity management, Hydrol. Process., 19, 30633080, https://doi.org/10.1002/hyp.5832, 2005.

Lamontagne, S., Taylor, A. R., Cook, P. G., Crosbie, R. S., Brownbill, R., Williams, R. M., and Brunner, P.: Field assessment of surface water-groundwater connectivity in a semi-arid river basin (Murray-Darling, Australia), Hydrol. Process., 28, 15611572, https://doi.org/10.1002/hyp.9691, 2014.

Levitt, M. H.: Spin Dynamics: Basics of Nuclear Magnetic Resonance, John Wiley \& Sons, Chichester, New York, ISBN 0471489220, 2001.

Lowrie, W.: Fundamentals of Geophysics, Cambridge University Press, Cambridge, 2007.

Markovich, K. H., Manning, A. H., Condon, L. E., and McIntosh, J. C.: Mountain-Block Recharge: A Review of Cur- rent Understanding, Water Resour. Res., 55, 8278-8304, https://doi.org/10.1029/2019WR025676, 2019.

Mavko, G., Mukerji, T., and Dvorkin, J.: The Rock Physics Handbook: Tools for Seismic Analysis of Porous Media, 2nd Edn., Cambridge University Press, Cambridge, https://doi.org/10.1017/CBO9780511626753, 2009.

Mokhtar, T. A., Herrmann, R. B., and Russell, D. R.: Seismic velocity and $Q$ model for the shallow structure of the Arabian Shield from short-period Rayleigh waves, Geophysics, 53, 1379-1387, https://doi.org/10.1190/1.1442417, 1988.

Moser, T.: Shortest-Path Calculation of Seismic Rays, Geophysics, 56, 59-67, https://doi.org/10.1190/1.1442958, 1991.

Moser, T. J., Nolet, G., and Snieder, R.: Ray bending revisited, B. Seismol. Soc. Am., 82, 259-288, 1992.

Neducza, B.: Stacking of surface wavesSSW provides high-quality dispersion, Geophysics, 72, V51-V58, https://doi.org/10.1190/1.2431635, 2007.

Nur, A. and Simmons, G.: The effect of saturation on velocity in low porosity rocks, Earth Planet. Sc. Lett., 7, 183-193, https://doi.org/10.1016/0012-821X(69)90035-1, 1969.

O'Neil, A.: Full-waveform reflectivity for modeling, inversion and appraisal of seismic surface wave dispersion in shallow site investigations, $\mathrm{PhD}$ thesis, University of Western Australia, Perth, 2003.

Orlando, J., Comas, X., Hynek, S. A., Buss, H. L., and Brantley, S. L.: Architecture of the deep critical zone in the Río Icacos watershed (Luquillo Critical Zone Observatory, Puerto Rico) inferred from drilling and ground penetrating radar (GPR): Drilling and GPR explore weathering in the Rio Icacos LCZO watershed, Earth Surf. Proc. Land, 41, 1826-1840, https://doi.org/10.1002/esp.3948, 2016.

Parasnis, D. S.: Principles of Applied Geophysics, 4th Edn., Chapman and Hall, New york, USA, https://doi.org/10.1007/978-94009-4113-7, 1986.

Park, C. B., Miller, R. D., and Xia, J.: Multichannel analysis of surface waves, Geophysics, 64, 800-808, https://doi.org/10.1190/1.1444590, 1999.

Parsekian, A. D., Singha, K., Minsley, B. J., Holbrook, W. S., and Slater, L.: Multiscale geophysical imaging of the critical zone: Geophysical Imaging of the Critical Zone, Rev. Geophys., 53, 1-26, https://doi.org/10.1002/2014RG000465, 2015.

Pasquet, S. and Bodet, L.: SWIP: An integrated workflow for surface-wave dispersion inversion and profiling, Geophysics, 82 WB47-WB61, https://doi.org/10.1190/geo2016-0625.1, 2017.

Pasquet, S., Bodet, L., Dhemaied, A., Mouhri, A., Vitale, Q., Rejiba, F., Flipo, N., and Guérin, R.: Detecting different water table levels in a shallow aquifer with combined P-, surface and SH-wave surveys: Insights from VP/VS or Poisson's ratios, J. Appl. Geophys., 113, 38-50, https://doi.org/10.1016/j.jappgeo.2014.12.005, 2015a.

Pasquet, S., Bodet, L., Longuevergne, L., Dhemaied, A., Camerlynck, C., Rejiba, F., and Guérin, R.: 2D characterization of near-surface: surface-wave dispersion inversion versus refraction tomography, Near Surf. Geophys., 13, 315-332, https://doi.org/10.3997/1873-0604.2015028, 2015 b.

Pasquet, S., Holbrook, W. S., Carr, B. J., and Sims, K. W. W.: Geophysical imaging of shallow degassing in a Yellowstone hydrothermal system: Imaging Shallow Degassing 
in Yellowstone, Geophys. Res. Lett., 43, 12027-12035, https://doi.org/10.1002/2016GL071306, 2016.

Prasad, M.: Acoustic measurements in unconsolidated sands at low effective pressure and overpressure detection, Geophysics, 67, 405-412, https://doi.org/10.1190/1.1468600, 2002.

Rayment, G. E. and Higginson, F. R.: Australian laboratory handbook of soil and water chemical methods, Inkata Press, Port Melbourne, Australia, available at: https://trove.nla.gov.au/version/ 45465694 (last access: 27 June 2019), 1992.

Raymond, P. A., Hartmann, J., Lauerwald, R., Sobek, S., McDonald, C., Hoover, M., Butman, D., Striegl, R., Mayorga, E., Humborg, C., Kortelainen, P., Dürr, H., Meybeck, M., Ciais, P., and Guth, P.: Global carbon dioxide emissions from inland waters, Nature, 503, 355-359, https://doi.org/10.1038/nature12760, 2013.

Reynolds, J. M.: An introduction to applied and environmental geophysics, 2nd Edn., Wiley-Blackwell, Chichester, UK, available at: https://trove.nla.gov.au/version/50745015 (last access: 27 June 2019), 2011.

Robinson, D. A., Campbell, C. S., Hopmans, J. W., Hornbuckle, B. K., Jones, S. B., Knight, R., Ogden, F., Selker, J., and Wendroth, O.: Soil Moisture Measurement for Ecological and Hydrological Watershed-Scale Observatories: A Review, Vadose Zone J., 7, 358, https://doi.org/10.2136/vzj2007.0143, 2008.

Rücker, C., Günther, T., and Wagner, F. M.: pyGIMLi: An open-source library for modelling and inversion in geophysics, Comput. Geosci., 109, 106-123, https://doi.org/10.1016/j.cageo.2017.07.011, 2017.

Salem, H. S.: Poisson's ratio and the porosity of surface soils and shallow sediments, determined from seismic compressional and shear wave velocities, Géotechnique, 50, 461-463, https://doi.org/10.1680/geot.2000.50.4.461, 2000.

Sambridge, M.: Geophysical inversion with a neighbourhood algorithm - I. Searching a parameter space, Geophys. J. Int., 138, 479-494, https://doi.org/10.1046/j.1365-246X.1999.00876.x, 1999.

Scanlon, B. R., Healy, R. W., and Cook, P. G.: Choosing appropriate techniques for quantifying groundwater recharge, Hydrogeol. J., 10, 18-39, https://doi.org/10.1007/s10040-001-0176-2, 2002.

Scanlon, B. R., Keese, K. E., Flint, A. L., Flint, L. E., Gaye, C. B., Edmunds, W. M., and Simmers, I.: Global synthesis of groundwater recharge in semiarid and arid regions, Hydrol. Process., 20, 3335-3370, https://doi.org/10.1002/hyp.6335, 2006.

Shanafield, M. and Cook, P. G.: Transmission losses, infiltration and groundwater recharge through ephemeral and intermittent streambeds: A review of applied methods, J. Hydrol., 511, 518529, https://doi.org/10.1016/j.jhydrol.2014.01.068, 2014.

Sheehan, J. R., Doll, W. E., and Mandell, W. A.: An evaluation of methods and available software for seismic refraction tomography analysis, J. Environ. Eng. Geophys., 10, 21-34, 2005.

Siemon, B., Christiansen, A. V., and Auken, E.: A review of helicopter-borne electromagnetic methods for groundwater exploration, Near Surf. Geophys., 7, 629-646, https://doi.org/10.3997/1873-0604.2009043, 2009.

Singha, K. and Gorelick, S. M.: Saline tracer visualized with three-dimensional electrical resistivity tomography: Field-scale spatial moment analysis, Water Resour. Res., 41, W05023, https://doi.org/10.1029/2004WR003460, 2005.
Smith, M. L., Fontaine, K., and Lewis, S. J.: Regional Hydrogeological Characterisation of the St Vincent Basin, South Australia: Technical report for the National Collaboration Framework Regional Hydrogeology Project, Geoscience Australia, Canberra, Australia, 2015.

Smith, W. and Wessel, P.: Gridding with continuous curvature splines in tension, Geophysics, 55, 293-305, https://doi.org/10.1190/1.1442837, 1990.

Stein, S. and Wysession, M.: An Introduction to Seismology, Earthquakes, and Earth Structure, Blackwell Publishing, Maldent, MA, USA, ISBN 0-86542-078-5, 2003.

Taylor, C. B., Brown, L. J., Cunliffe, J. J., and Davidson, P. W.: Environmental tritium and ${ }^{18} \mathrm{O}$ applied in a hydrological study of the Wairau Plain and its contributing mountain catchments, Marlborough, New Zealand, J. Hydrol., 138, 269-319, https://doi.org/10.1016/0022-1694(92)90168-U, 1992.

Telford, W. M., Geldart, L. P., and Sheriff, R. E.: Applied Geophysics, 2nd Edn., Cambrige University Press, New York, USA, ISBN 0-521-33938-3, 1990.

Thayer, D., Parsekian, A. D., Hyde, K., Speckman, H., Beverly, D., Ewers, B., Covalt, M., Fantello, N., Kelleners, T., Ohara, N., Rogers, T., and Holbrook, W. S.: Geophysical Measurements to Determine the Hydrologic Partitioning of Snowmelt on a SnowDominated Subalpine Hillslope, Water Resour. Res., 54, 37883808, https://doi.org/10.1029/2017WR021324, 2018.

Torrey, H. C.: Bloch Equations with Diffusion Terms, Phys. Rev., 104, 563-565, https://doi.org/10.1103/PhysRev.104.563, 1956.

Uyanık, O.: The porosity of saturated shallow sediments from seismic compressional and shear wave velocities, J. Appl. Geophys., 73, 16-24, https://doi.org/10.1016/j.jappgeo.2010.11.001, 2011.

Valois, R., Galibert, P.-Y., Guerin, R., and Plagnes, V.: Application of combined time-lapse seismic refraction and electrical resistivity tomography to the analysis of infiltration and dissolution processes in the epikarst of the Causse du Larzac (France), Near Surf. Geophys., 14, 13-22, https://doi.org/10.3997/18730604.2015052, 2016.

Walsh, D. O., Turner, P., Grunewald, E. D., Zhang, H., Butler, J. J., Reboulet, E., Knobbe, S., Christy, T., Lane, J. W., Johnson, C. D., Munday, T., and Fitzpatrick, A.: A Small-Diameter NMR Logging Tool for Groundwater Investigations, Groundwater, 51, 914-926, https://doi.org/10.1111/gwat.12024, 2013.

Walsh, D. O., Grunewald, E. D., Turner, P., Hinnell, A., and Ferre, T. P. A.: Surface NMR instrumentation and methods for detecting and characterizing water in the vadose zone, Near Surf. Geophys., 12, 271-284, https://doi.org/10.3997/1873-0604.2013066, 2014.

Wathelet, M., Jongmans, D., and Ohrnberger, M.: Surface-wave inversion using a direct search algorithm and its application to ambient vibration measurements, Near Surf. Geophys., 2, 211-221, https://doi.org/10.3997/1873-0604.2004018, 2004.

West, N., Kirby, E., Nyblade, A. A., and Brantley, S. L.: Climate preconditions the Critical Zone: Elucidating the role of subsurface fractures in the evolution of asymmetric topography, Earth Planet. Sc. Lett., 513, 197-205, https://doi.org/10.1016/j.epsl.2019.01.039, 2019.

Wilson, J. L. and Guan, H.: Mountain-block hydrology and mountain-front recharge, in: Water Science and Application, vol. 9, edited by: Hogan, J. F., Phillips, F. M., and Scanlon, B. 
R., American Geophysical Union, Washington, D.C., USA, 113137, 2004.

Winograd, I. J., Riggs, A. C., and Coplen, T. B.: The relative contributions of summer and cool-season precipitation to groundwater recharge, Spring Mountains, Nevada, USA, Hydrogeol. J., 6, 7793, https://doi.org/10.1007/s100400050135, 1998.

Winter, T. C., Harvey, J. W., Franke, O. L., and Alley, W. M.: Ground Water and Surface Water: A Single Resource, in: Circular, USGS Numbered Series 1139, US Geological Survey, North Dakota, USA, https://doi.org/10.3133/cir1139, 1998.

Xia, J., Miller, R. D., and Park, C. B.: Estimation of near-surface shear-wave velocity by inversion of Rayleigh waves, Geophysics, 64, 691-700, https://doi.org/10.1190/1.1444578, 1999.

Xia, J., Miller, R. D., Park, C. B., and Tian, G.: Inversion of high frequency surface waves with fundamental and higher modes, J. Appl. Geophys., 52, 45-57, https://doi.org/10.1016/S09269851(02)00239-2, 2003.
Xie, Y., Cook, P. G., Brunner, P., Irvine, D. J., and Simmons, C. T.: When Can Inverted Water Tables Occur Beneath Streams?, Groundwater, 52, 769-774, https://doi.org/10.1111/gwat.12109, 2014.

Zelt, C. A., Haines, S., Powers, M. H., Sheehan, J., Rohdewald, S., Link, C., Hayashi, K., Zhao, D., Zhou, H. -w., Burton, B. L., Petersen, U. K., Bonal, N. D., and Doll, W. E.: Blind Test of Methods for Obtaining 2-D Near-Surface Seismic Velocity Models from First-Arrival Traveltimes, J. Environ. Eng. Geophys., 18, 183-194, https://doi.org/10.2113/JEEG18.3.183, 2013. 